\title{
POSSIBILIDADE DE TRATAMENTO MÉDICO DA DISFUNÇÃO ERÉTIL
}

Antônio Pereira Bueno Filho ${ }^{1}$

\section{Introdução}

Revisaremos os tratamentos mais utilizados para a disfunção erétil de origem orgânica; porém, ressaltamos que é de fundamental importância o conhecimento das causas psicológicas, com o intuito de avaliar plenamente os nossos pacientes.

\section{Vacuoterapia}

0 uso de aparelhos que induzem a ereção através do vácuo é uma alternativa que pode produzir e manter o estado de ereção ou semi-ereção, suficiente para a penetração, em muitos portadores de disfunção erétil (DE).

Embora existam vários modelos disponiveis, estes aparelhos apresentam basicamente três componentes comuns:

- Câmara de vácuo

- Bomba de vácuo que produz pressão negativa no interior da câmara

- Anel constrictor, que é aplicado na base do pênis.

\footnotetext{
'Médico do Hospital Municipal da Piedade (R.J.) e do Centro de Investigação Urológica Mestre em Sexologia pela Universidade Gama Filho 
A criação de uma pressão negativa ao redor de 200 a $250 \mathrm{~cm}$. de $\mathrm{H} 20$, dentro do cilindro de acrílico ( câmara de vácuo), faz com que todos os tecidos do pênis tornem-se ingurgitados por sangue, produzindo uma ereção que é mantida por algum tempo com o auxílio de um anel de látex colocado na base do pênis, com o objetivo de impedir a saida de sangue pelo sistema venoso superficial. Uma geléia lubrificante é aplicada no pênis antes de ele ser introduzido no cilindro, o que assegura o completo vedamento, tornando, assim, o mecanismo de vacuoterapia mais eficiente.

As complicações da vacuoterapia são raras e incluem: dificuldade para ejacular, dor, desenvolvimento de parafimose, necrose da pele do pênis, aparecimento de petéquias na pele do pênis, desenvolvimento de doença de Peyronie, aparecimento de equimose e aparecimento de hematoma.

As vantagens da vacuoterapia são: simplicidade do método, não apresentar interferência com outros tratamentos, poder ser usado somente na ocasião desejada e poder melhorar as ereções naturais de alguns pacientes.

Suas desvantagens são: necessidade de destreza para a colocação do aparelho, produzir uma ereção não fisiológica; seu tempo máximo de uso é de trinta minutos, devendo o anel constrictor, localizado na base do pênis, ser retirado após este tempo.

A vacuoterapia promove ereção peniana suficiente para penetração vaginal em muitos homens, contudo, no Brasil, a aderência do paciente a este tipo de tratamento é bastante reduzida, talvez pelo alto preço do aparelho de boa qualidade, pelo preconceito dos pacientes e até pela não indicação dos médicos, que julgam ser este método pouco prático para seus pacientes.

\section{Drogas de Uso Intra-uretral}

A utilização da via intrauretral para a adminstração de drogas vasoativas é uma opção de tratamento da DE e sugere a comunicação entre o corpo esponjoso e os corpos cavernosos. Das drogas de adminstração intra-uretral, o alprostadil é a que tem apresentado melhores resultados 
à prostaglandina E1 ( PGE1) e atua promovendo um aumento da concentração da adenosina monofostato (AMP) intracelular e relaxamento da musculatura lisa.

\section{Método de Aplicação:}

Ele é um pequeno supositório, que vem dentro de um dispositivo plástico para aplicação no terço distal da uretra. 0 paciente é orientado a urinar antes, pois a urina residual na uretra facilita a penetração do dispositivo aplicador de plástico e favorece a diluição do pequeno supositório, que é absorvido pela mucosa uretral e chega aos corpos cavernosos através de prováveis comunicações vasculares entre este e o corpo esponjoso, que envolve a uretra. Orienta-se que a aplicação seja realizada com o paciente sentado e com o pênis retificado, seguindo-se dez minutos de massagem no pênis para facilitar a absorção do remédio. Recomenda-se o uso de preservativo peniano, quando a parceira estiver grávida, devido ao risco potencial de abortamento.

Complicações: dor peniana, ardência uretral, sangramento pela uretra, hipotensão arterial e sincope.

Contra-Indicações : hipersensibilidade conhecida ao alprostadil, anomalias congênitas da uretra, estenoses uretrais, uretrites, balanopostites.

Os resultados clínicos com seu uso variam de 7\% a 65\% de produção de ereções rígidas, em niveis suficientes para a penetração vaginal, sendo que, segundo o I Consenso Brasileiro de Disfunção Erétil, os estudos brasileiros demonstram que seu sucesso ocorre em cerca de 7\% dos casos; é de difícil aderência pelos pacientes, principalmente pelo efeito secundário de ardência uretral.

\section{Drogas Intracavernosas}

As drogas empregadas em farmacoterapia intracavernosa podem ser aplicadas isoladamente, como monoterapia, ou em associação de duas 
drogas ( chamado "bimix" ) ou em associação de três drogas (chamado "trimix").A literatura mundial relata o aparecimento de ereção suficiente para a penetração vaginal em cerca de 65\% a $85 \%$.

\section{Drogas Intracavernosas Mais Utilizadas:}

1) Cloridrato de papaverina: é um alcalóide extraido do opium papaver somniferum, cuja principal ação farmacológica é promover o relaxamento da musculatura lisa e, portanto, atua nesta, ao nivel das artérias helicinais e dos sinusóides dos corpos cavernosos. Sua metabolização ocorre no fígado e sua meia vida plasmática é de uma a duas horas, mas, como sua eliminação é lenta, pode levar a ereções prolongadas. Pode ser conservada sob temperatura ambiente.

2) Mesilato de fentolamina: é um antagonista alfa-adrenérgico, que é metabolizado no fígado e possui meia-vida plasmática de trinta minutos. Uma vez aplicado nos corpos cavernosos, relaxa a musculatura lisa das artérias cavernosas e helicinais, provocando uma tumescência peniana. Esta droga não apresenta efeito relaxante sobre a musculatura lisa dos sinusóides dos corpos cavernosos e, em virtude disto, sozinha não é capaz de produzir uma ereção, dai ser usada associada à papaverina ou à prostaglandina $\mathrm{E} 1$, reduzindo assim a quantidade destas outras drogas e potencializando a resposta erétil.

3) Prostaglandina E1 (PGE1): é um ácido graxo natural que relaxa a musculatura lisa. Injetada nos corpos cavernosos, relaxa a musculatura lisa dos sinusóides e das artérias helicinais. Sua meia-vida plasmática é inferior a um minuto, devido a sua rápida metabolização pulmonar, que corresponde à eliminação cerca de $80 \%$ do que foi administrado na primeira passagem da droga pelos pulmões. 0 alprostadil, que é a forma sintética da PGE, é a única droga vasoativa que tem o seu uso intracavernoso mundialmente aprovado.

Contra-indicações para Injeção de Drogas Intracavernosas: alergia à medicação intracavernosa empregada, presença de infecção peniana, 
ou dermatite; coagulopatias, uso regular de inibidores da amino-oxidase (MA0), doenças psiquiátricas graves, psicopatias, passado de priapismo idiopático, doenças cardiovasculares graves, pacientes que não possuem coordenação motora suficiente para realizarem a auto-aplicação, portadores de doença de Parkinson, pacientes com acuidade visual reduzida, leucemia e mieloma múltiplo.

Complicações da Injeção Intracavernosa: a principal é o priapismo, dor no local da injeção, hematomas, equimoses, fibrose dos corpos cavernosos.

Método de Uso das Drogas Intracavernosas: o paciente deve ser orientado para auto-injetar o medicamento de maneira segura, eficaz, e usando o volume minimo necessário para a obtenção de ereção suficiente para penetração vaginal satisfatória e com duração de trinta a quarenta minutos. 0 paciente deve receber orientação médica e, antes de realizar autoaplicações em casa, deverá fazer este procedimento sob supervisão, no consultório. Alertar que, no caso de ocorrerem ereções prolongadas (acima de três horas), o médico deverá ser contatado imediatamente, pois pode estar ocorrendo priapismo.A freqüência recomendada para a aplicação é de duas a três vezes na semana, sempre alternando o lado aplicado.

Principais Causas de Abandono do Tratamento Com Drogas Intracavernosas:

- Retorno a ereções espontâneas

- Resposta inadequada ou insuficiente para que ocorra a penetração

- Aparecimento de complicações

- Temor das agulhas e injeções, ou o paciente fica saturado de ter que tomar uma agulhada, toda vez que quiser manter uma relação sexual

- Discórdias conjugais: muitas vezes a parceira passa a ser hostil com o paciente, julgando que ele já não sente mais atração física por ela e que, para realizarem sexo, ele tem que usar uma medicação. 


\section{Próteses Penianas}

As próteses penianas, a principio, devem ser utilizadas quando todos os outros meios de tratamento tenham falhado. É de suma importância esclarecer, ao paciente, sobre a irreversibilidade desta cirurgia, devido à destruição dos sinusóides dos corpos cavernosos; apresentar, ao mesmo, os diversos tipos de próteses (semi-rígida e inflável), esclarecer as vantagens e desvantagens entre elas e suas possiveis complicações. É aconselhável que o paciente assine o consentimento para esta cirurgia.

0 paciente também deverá ser submetido a uma avaliação psicológica criteriosa, para que não tenha ilusões quanto ao resultado e não alimente falsas expectativas. Verificar se ele nutre a expectativa de aumento da dimensão de seu pênis após a colocação da prótese, pois o que ocorre, na realidade, são pequenas modificações no volume e no comprimento do pênis em relação à ereção normal. Explicar também que não haverá modificações da libido ou do orgasmo e que alguns pacientes apresentam alteração da sensibilidade, com o uso de prótese. Devemos comunicar, à parceira, todos esses detalhes e, se houver problemas no relacionamento do casal, este deve realizar terapia sexual prévia e permanecer em acompanhamento terapêutico após o implante da prótese. Devemos evitar a prótese peniana em pacientes com alto nivel de ansiedade, deprimidos ou que tenham baixa auto-estima. Em síntese, a prótese resolve somente o problema de rigidez e da dificuldade de penetração.

\section{Tipos de Próteses:}

1-Rigidas: atualmente quase não são utilizadas.

2-Semi-rígidas: na grande maioria, são formadas por uma camada de silicone de consistência firme, que reveste outra camada de silicone macio e ambas envolvem uma cordoalha de prata ou de aço, o que permite uma boa rigidez e dá, à prótese, uma maleabilidade satisfatória. As hastes de aço são mais resistentes à quebra, porém são menos flexíveis do que as hastes de prata. Essas próteses são confeccionadas em vários comprimentos e diâmetros. Há também modelos confeccionados com segmentos proximais ou distais, que podem ser encaixados, ou retirados, 
aumentando assim o comprimento de acordo com a medida dos corpos cavernosos do paciente. 0 diâmetro da prótese é calculado tomando-se por base a espessura do pênis e, em algumas, podemos retirar algumas camadas do revestimento de silicone, com o intuito de melhor adaptála às medidas do paciente. As próteses semi-rígidas são tecnicamente mais fáceis de implantar e o seu custo é bem menor do que as infláveis.

Suas desvantagens são: a dificuldade em ocultá-las, pois mesmo flexionadas fazem volume, o que pode levar a constrangimento em saunas, vestiários de clubes, academias, e dificultam a realização da endoscopia urinária (uretrocistoscopias, ressecções transuretrais).

3) Prótese Inflável: estas, em deflação, ficam flácidas e, quando acionamos seu mecanismo de inflação, ficam rígidas. 0 paciente que as usa mantém um volume genital mais próximo do fisiológico. Elas podem ser:

a) Próteses de dois volumes: consistem de dois cilindros infláveis, conectados a um reservatório que está acoplado a uma bomba. Este reservatório, com a bomba, é colocado no interior do escroto, entre os testículos.

b) Próteses de três volumes: estas apresentam dois cilindros, uma bomba que fica localizada no escroto e um reservatório que fica colocado na região abdominal, atrás do púbis. Necessitam de uma certa habilidade manual para o seu manuseio, mas são as que produzem as ereções mais semelhantes às naturais.

As próteses penianas podem apresentar complicações, tais como: hematomas, perfuração da túnica albugínea do corpo cavernoso, lesão da uretra, retenção urinária, erros na escolha do tamanho dos cilindros e/ou das hastes, fibrose peniana, dor persistente, infecção e defeitos mecânicos das próteses. A sua colocação é sempre uma intervenção cirúrgica e, como tal, deve ser cercada de todos os cuidados préoperatórios inerentes a uma cirurgia e ser realizada por urologistas tecnicamente preparados para efetuá-la com segurança. 